The Olivieri symposium

\title{
The Olivieri debacle: where were the heroes of bioethics? A Reply
}

M Rowell

In her reply to Baylis the author takes the opportunity to "clarify, and in some cases to correct, some facts"

am pleased to see Dr Baylis's article relating to the Olivieri case at the Hospital for Sick Children and the University of Toronto. I thank her for the many facets of that case that she has articulated. Nonetheless, as the bioethicist most closely connected with the case at the clinical level I would like to take this opportunity to clarify, and in some cases to correct, some facts.

Dr Baylis entitles her section on the role of bioethics as "Stories of silence". I differ from this view. Perhaps the stories are less stories of silence than stories to which others have not listened.

I wish to make it quite clear that I have always supported Dr Olivieri and her colleagues in their actions with respect to the research that is at the centre of this case. I have been public in my support and I continue to be so.

My departure from the Hospital for Sick Children was in no way caused by the Olivieri case. I was offered a challenging position at another Ontario hospital that fitted well with my professional goals and formed a part of a wider personal and positive discernment process. It may be the case that such a decision was made easier by the stresses and the sheer volume of work entailed in the Olivieri situation.

During my years as a bioethicist at the Hospital for Sick Children, and during this case, I always received the greatest support from Dr Christine Harrison, director of the Department of Bioethics. With respect to the Olivieri case my position was not "junior" to Christine Harrison's. Relations in the department were collegial and not hierarchical as Baylis presumes. My involvement as a bioethicist was agreed, mutually based on our relative strengths and backgrounds. My experience and record in research ethics made me the logical person to speak for the department on this issue within and outside the hospital.
My efforts to support Dr Olivieri were often dismissed by the hospital administration and sometimes also by the media, who were perhaps seeking a more sensational account of the case than I felt it appropriate to provide, believing such an approach to be contrary to the best interests of children in research and contrary to support of Dr Olivieri and her colleagues. In the hospital I actively argued strongly for Olivieri and there are letters to support this fact in the public archives of the Hospital for Sick Children. In particular, I requested that the Hospital initiate a truly independent review, a suggestion that was not accepted. On several occasions I spoke with news reporters who sought my opinion. In those interviews I consistently and without reservation, supported Dr Olivieri's position and I was critical of the hospital for its lack of support for Olivieri and her colleagues, and for what I saw as the hospital's misreading of the issues at hand in the case. I have always publicly supported the view that "given her interpretation of the data at the time Olivieri had no choice but to do what she did" (for the wellbeing and safety of children in research) (personal transcript of Dr M Shuchman in an interview on "Quirks and Quarks", CBC). I contributed in this vein to both the Naimark report and the report completed by the Canadian Association of University Teachers; the latter being a review that I believe to provide a public report of integrity. ${ }^{1}$ In numerous cases I was not quoted despite my willingness to be so; a point of concern and disappointment to me.

In addition to the wider public support offered I spoke for Olivieri, and in a manner critical of the handling of the case by the hospital, at two meetings of the Canadian Bioethics Society, in numerous public presentations, and at hospital and university rounds and lectures.

Perhaps Baylis is correct that I should have done more. What more I might have done, at that time, is unclear to me. In arguing, however, after the fact of another's actions, as Baylis does of mine, it is important to have the correct and clear facts.

Finally, it is important that readers of this article and this symposium understand that I retain respect for Nancy Olivieri as a professional. I honour the courage and the integrity of Dr Olivieri and of her close supporters, Drs Helen Chan, John Dick, Peter Durie, and Brenda Gallie. They have taught us much about research integrity and they continue to do so. Within recent weeks I have committed to continue to work with them whenever they need help with respect to other issues that have arisen as a consequence of the initial case. I am comfortable with a public articulation of my support.

Importantly too, my affection and respect for the Hospital for Sick Children remains strong. Every institution has its failings and its internal problems. My view is that in the Olivieri case and its sequelae the hospital publicly demonstrated such failings. What can be hoped for is that situations such as this teach us well how to proceed in the future. That said, the hospital's long standing and continuing record in almost every area of teaching, research, and most especially patient care, is exemplary. Readers considering this symposium should do so with this perspective in mind. I am proud to have been associated with the Hospital for Sick Children for a period of eight years and I am privileged to have worked with doctors of courage and integrity such as Dr Olivieri and her supporters, and indeed so many fine physicians who daily work with total commitment for children in need.

J Med Ethics 2004;30:50.

doi: 10.1136/jme.2003.007484

\section{Author's affiliation}

M Rowell, The Canadian Catholic Bioethics Institute, St Michael's College, University of Toronto, Toronto, Canada; mary.rowell@utoronto.ca

\section{REFERENCE}

1 Thompson J, Baird P, Downie J. The Olivieri report: the complete text of the report of the independent inquiry commissioned by the Canadian Association of University Teachers. Toronto: James Lorimer and Co, 2001. 


\section{Response to Mary Rowell}

\section{F Baylis}

In responding to Ms Rowell's commentary on her original paper the author points out that the job of all bioethicists, namely, speaking truth to power, is a daunting task which is unlikely to succeed "if we do not learn to ask for and to accept, to offer and to provide, moral support and meaningful help."

In

my article "The Olivieri debacle: where were the heroes of bioethics?"1 I make four comments about Ms Rowell's involvement in the case. In my first comment relating to Ms Rowell, I suggest that a careful reader of the Naimark report could reasonably conclude "that the role of bioethics in helping to resolve the controversy was, at best, very limited". In reaching this conclusion, I relied on the findings of the two official reports/inquiries about this case. Though the two reports reach different conclusions about the case, there appears to be agreement on the very limited role of bioethics. As noted in my original article, in the 160 page Naimark report there are but a few paragraphs about bioethics and Ms Rowell's role in the Olivieri case. This is surprising, and I say as much in my article. In the 540 page report of the Committee of Inquiry, which Ms Rowell describes as "a review that I believe to provide a public report of integrity", little more detail is provided regarding Ms Rowell's role. I included all references to Ms Rowell from the first report in the original article. I did not do so with the second report. This was not done to diminish any contribution(s) Ms Rowell might have made. In my view, no new evidence germane to the points I wanted to make was provided in the text that I did not include in my article.

In light of Ms Rowell's concerns that her role in the Olivieri affair is not properly described, I offer here the information about Ms Rowell contained in the Committee of Inquiry report.

In June 1998, Professor Rowell was asked to intercede by $\operatorname{Dr}$ Durie and she agreed to do so. She approached Dr Buchwald, who suggested she undertake a review of the facts of the matter, as a preliminary step to a mediation process. Professor Rowell agreed and in discussions with Dr Buchwald drew up terms of reference and a list of persons to interview. She was to report on facts and make suggestions on helpful courses of action from a bioethics perspective, with a view to getting "everyone around the same table" eventually. The list of persons she interviewed included several members of the hospital executive, and Drs Olivieri, Chan, Dick, Durie, and Gallie. Following the round of interviews, Professor Rowell concluded that mediation efforts would be futile. She told this Committee that she subsequently decided to offer support to Dr Olivieri in the ethical stand she took on the need to inform trial participants of a risk. ${ }^{2}$

The only other reference to Ms Rowell in the Committee of Inquiry report appears on page 257 and the relevant excerpt is quoted in my original article. The reader now has the complete official record of Ms Rowell's participation in the case as represented in the two official reports/inquiries. I am sure there is much more to tell than is on the record and I sincerely hope that one day Ms Rowell will tell the rest of the story. Until then, commentators only have the formal record to rely upon.

Ms Rowell objects to my second comment in the original article that describes her as the more junior member of the bioethics department. This description was not meant to offend, but simply to reflect the fact that the department of bioethics had a director. Ms Rowell describes her relationship with Dr Harrison as collegial and not hierarchical. Collegial relations notwithstanding, Ms Rowell reported to Dr Harrison and was, therefore, within the formal administrative structure of the department, the more junior member. Ms Rowell further states that she was the "person to speak for the department on this issue within and outside the hospital." This description is not consistent with my experience in this case. Correspondence directed by myself and colleagues to the hospital administration about this affair was answered by Dr Harrison, not Ms Rowell (C Harrison, personal communication, 1999).

The third comment about Ms Rowell concerns the following quote from a media article: "...she was treated so rudely by the hospital executive when she raised concerns about the Olivieri affair that she considered resigning". This quote is followed by my statement: "Indeed, she did eventually resign." While this statement is accurate, a reader might conclude from the juxtaposition of the quote and my statement that there was a causal connection between the decision to resign and the Olivieri case. Ms Rowell insists that her "departure from the Hospital for Sick Children was in no way caused by the Olivieri case". Ms Rowell does allow, however, that there may have been a connection: "It may be the case that such a decision was made easier by the stresses and sheer volume of the work entailed in the Olivieri situation"; she merely denies that the connection was causal. I should therefore make clear that the juxtaposition implies a connection but not necessarily a causal connection. Further to this, I should like to add that I do not believe that I am "arguing ... after the fact of another's actions .... [without] correct and clear facts." To my knowledge, I am only accurately reporting information already in the public domain-either in one or other of the official reports/inquiries or in public comments made by Ms Rowell. I readily acknowledge that information in the public domain may not be full information.

The fourth comment about Ms Rowell in the original article is that she "has chosen to remain silent and she has never publicly told her story. The closest she has come to doing so was at the 13th Annual meeting of the Canadian Bioethics Society in the Fall of 2001. During the question period after a plenary lecture titled A Reflection on the 'Place' of Bioethics, ${ }^{3}$ which criticised the Canadian bioethics community at large for its silence on two internationally prominent ethics cases originating in Toronto-one involving Dr Nancy Olivieri, the other involving Dr David Healy-Ms Rowell spoke passionately from the floor about the unbearable stress and lack of institutional support she experienced while involved in this case in her official capacity as bioethicist. She indicated that she had no choice but to leave her position at the hospital." Prior to Ms Rowell's replies to my article, ${ }^{45}$ that statement was true. In her print reply to my article, she insists 
she was a vocal supporter of Dr Olivieri but this is a separate issue from whether Ms Rowell has ever publicly told her story. Ms Rowell was invited to contribute an article to the special symposium on the Olivieri case but did not do so. I am glad that my article has prompted her to write about her experience and I sincerely hope she will write in more detail soon.

In closing, I should say that I believe that Ms Rowell did her best under very difficult circumstances. Ms Rowell writes that "Perhaps Baylis is correct that I should have done more. What more I might have done, at that time, is unclear to me." For the record, my comment about doing more was not directed to Ms Rowell, but to all Canadian bioethicists-this includes Ms Rowell, but it also includes myself. What more could I have done? With the benefit of hindsight, I believe that I should have pursued matters further than I did. What more could Ms Rowell have done? She could, among other things, have accepted offers of assistance from other bioethicists across the country who were prepared to take a stand. What could the Canadian bioethics community have done? It could, among other things, have come together and acted in concert to support the bioethicists in the local institution, to explain the issues raised in the case to the public, and to lobby for law and policy reform necessary to ensure that such a case would never happen again anywhere in Canada.

The lesson for all of us in this is that speaking truth to power-the job of bioethics-is a daunting task and one that we are unlikely to succeed at if we do not learn to ask for and to accept, to offer and to provide, moral support and meaningful help.

$J$ Med Ethics 2004;30:51-52.

doi: 10.1136/jme.2003.007724
Correspondence to: F Baylis, Department of Bioethics and Department of Philosophy; Dalhousie University, Halifax, Nova Scotia, Canada B3H 4H7; Francoise.Baylis@Dal.Ca

\section{REFERENCES}

1 Baylis F. The Olivieri debacle: Where were the heroes of bioethics? J Med Ethics 2004;30:44-9.

2 Thompson J, Baird P, Downie J. Report of the Committee of Inquiry on the case involving $\mathrm{Dr}$ Nancy Olivieri, the Hospital for Sick Children, the University of Toronto and Apotex Inc. Toronto: CAUT, 2001:215.

3 Baylis F. A reflection on the "place" of bioethics. Canadian Bioethics Society, 13th Annual Meeting and Conference, Winnipeg, Manitoba, October 11-14, 2001. http://www.bioethics.ca/english/ am/baylis20001/cbs2001 b2.ppt (accessed 24 Nov 2003)

4 http://ime.bmijournals.com/misc/ advanced.shtml laccessed 24 Nov 2003 originally posted 21 Nov 2003; replaced $30 \mathrm{Nov}$ 2003).

5 Rowell M. Commentary: The Olivieri debacle: where were the heroes of bioethics? A reply. J Med Ethics 2004;30:50. http:// jme.bmijournals.com/misc/advanced.shtm (accessed 22 Dec 2003).

support, and reputations. We need more solidarity and collegiality. We should be able to call on colleagues to support us, to write and act jointly for some moral cause. Bioethics organisations should not simply function to run conferences and other junkets but should serve as a resource for collective and effective action.

When I worked as a registrar in an emergency department, I often consulted others about difficult decisions before I acted. This was one of the great benefits of the emergency room. Bioethics is often a solitary enterprise where bioethicists are expected to be final experts or to be able to provide the right answer in a priestly tradition. Practical ethics should be about sharing responsibility and collective action. Someone must finally lead or act, but there is too little collegial support of each other in bioethics. We should draw more on collections of expertise in institutes, organisations, list servers, and other groups of experts. Baylis describes as science fiction individual bioethicists being galvanised into collective action to write academic articles, and contribute to public debate and government policy. She dreams of bioethics societies contributing to policy formation and influencing practice. To realise these dreams is to learn from the Olivieri affair.

J Med Ethics 2004;30:52.

doi: 10.1136/jme.2003.007690

Correspondence to: Julian Savulescu, Department of Philosophy, University of Oxford, Oxford, UK:

julian.savulescu@philosophy.ox.ac.uk

\section{REFERENCE}

1 Baylis F. The Olivieri debacle: where were the heroes of bioethics? J Med Ethics 2004;30:50. professionals who have taken a heroic stand on a controversial ethical issue. In risky, and demanding, but together, we can benefit from each others' insights, 